\title{
Influence of size- and sex-biased harvesting on reproduction of the coconut crab Birgus latro
}

\author{
Taku Sato*, Kenzo Yoseda \\ Ishigaki Tropical Station, Seikai National Fisheries Research Institute, Fisheries Research Agency, Ishigaki, \\ Okinawa 907-0451, Japan
}

\begin{abstract}
Larger individuals of many biological resources are more likely to be caught than smaller ones. However, larger individuals can contribute disproportionately to reproduction through sexual selection. Therefore, it is likely that size-selective harvesting of larger individuals can lead to a decline in the reproductive output. Populations of the coconut crab Birgus latro have been severely depleted in most habitats due to overharvesting. Thus, to understand the harvesting pattern and determine its impacts on coconut crab reproduction, we investigated the size and sex of crabs that are marketed for consumption. The harvested population structure and the relationship between male body size and mating success were determined using market research, field investigations, and laboratory experiments. The harvesting pattern was sex- and body size-biased, in which larger males (>40 mm thoracic length) were exclusively taken. Sex ratio was skewed significantly toward females and mean male size decreased in the harvested population. Most female coconut crabs were estimated to mate only with males that are larger than or approximately equal to themselves in body size, implying female preference for larger males as mates. The present large male-selective harvesting could lead to depletion of the resource through reduced reproductive output brought about by reduced probability of encountering potential mates. Therefore, we recommend male-only harvesting with slot size limits as an effective management measure for coconut crabs.
\end{abstract}

KEY WORDS: Birgus latro $\cdot$ Mate choice $\cdot$ Male-only harvesting $\cdot$ Mating success $\cdot$ Reproductive rate Slot size limits

Resale or republication not permitted without written consent of the publisher

\section{INTRODUCTION}

Hunting and fishing are usually nonrandom and often size-selective, with larger individuals being more likely to be caught than smaller ones (Fenberg \& Roy 2008). Recently, it has been clarified that size-selective harvesting induces negative ecological and evolutionary consequences for many species of vertebrates and invertebrates (Fenberg \& Roy 2008). Although most stock management plans often mandate a minimum legal size limit for catches, the risk of such negative effects is still not being considered in most management plans for biological resources (Conover \& Munch 2002).

Body size is one of the key determinants of fitness in both males and females in a wide range of taxa (Andersson 1994). For example, body size is positively correlated with reproductive fitness (e.g. mating suc- cess and fecundity). Larger males are usually stronger competitors for females (Hoefler 2007), can provide more ejaculated sperm (Sato \& Goshima 2007a), or better care for offspring (Kolm 2002). In females, body size positively correlates with egg size (Einum \& Fleming 1999), number of eggs spawned (Sato \& Goshima 2006), and quality of larvae (Berkeley et al. 2004). Therefore, mate choice is nonrandom in the majority of animal species (Real 1990), and males and females mutually prefer larger mates (e.g. Aquiloni \& Gherardi 2008), resulting in larger individuals contributing disproportionately to reproduction of populations through sexual selection. Therefore, it is likely that size-selective harvesting of larger individuals with higher reproductive potential can lead to a decline in the reproductive output of the resources in certain cases (Sato \& Goshima 2006, Sato et al. 2007, Milner et al. 2007). 
The coconut crab Birgus latro (Linnaeus, 1767) lives on oceanic islets and atolls as well as coastal areas of the tropical Indo-Pacific region. However, populations in most habitats have been severely depleted or have virtually become extinct. Overharvesting (Fletcher 1993) and habitat destruction (IUCN 2009) have been considered to be among the causes of the present resource depletions. Despite the present depletion, there have been few serious attempts to manage the resources in any regions based on scientific evidence (Brown \& Fielder 1991). To predict the status and improve stocks of targeted species, it is important to investigate details of the mating system and reproductive ecology, e.g. intra- and inter-sexual selection, sizedependent reproductive potential, and size at functional maturity. However, little is known about the harvesting pattern and details of coconut crab reproductive biology. This lack of knowledge prevents us from understanding whether the present harvesting has negative impacts on its reproductive rate, and from establishing optimal management plans to conserve the resource.

Thus, in this study, we investigated (1) the size and sex of crabs that are marketed for consumption using market research to understand the harvesting pattern; (2) the population structure of harvested coconut crabs to estimate the effects of the observed harvesting pattern on the population structure; (3) we estimated the body size of males participating in reproduction during field investigation to examine the possible impact of the observed harvesting pattern on reproduction of the resources; (4) we analyzed the effect of size differences between males and females in mating pairs on mating success in laboratory experiments.

\section{MATERIALS AND METHODS}

Study sites. Market research was conducted on Ishigaki Island $\left(24^{\circ} 34^{\prime} \mathrm{N}, 123^{\circ} 16^{\prime} \mathrm{E}\right)$ on the Sakishima archipelago that consists of 18 islands (southwest of Okinawa, Japan). In the archipelago, coconut crabs have been traditionally eaten by locals but their abundance has decreased in recent years (Shokita 2006). Recently, coconut crabs have been served to tourists in some restaurants and bars on Ishigaki Island.

All field investigations were conducted on Hatoma Island $\left(24^{\circ} 28^{\prime} \mathrm{N}, 123^{\circ} 49^{\prime} \mathrm{E}\right)$, which is a small island $\left(\sim 4 \mathrm{~km}\right.$ in girth, $\left.0.96 \mathrm{~km}^{2}\right)$ also on the Sakishima archipelago. The reproductive season on this island starts in early June and terminates in late August (Sato \& Yoseda 2008).

All laboratory experiments were conducted at the Ishigaki Tropical Station, Seikai National Fisheries Research Institute.
Study species. Previous studies of coconut crabs have reported differences in size between sexes, with males growing to a much larger size than females (Fletcher et al. 1991). Males deposit a spermatophore mass over the gonopores of the female abdomen during mating. The attached spermatophores are retained by mated females until egg extrusion, and fertilization occurs externally (Fletcher 1993). The duration between mating and egg extrusion is presumed to be $<1 \mathrm{wk}$ (Sato \& Yoseda 2009). The size at functional maturity in females is estimated at $24.5 \mathrm{~mm}$ thoracic length (TL) (Sato \& Yoseda 2008), and all males on Hatoma Island $>25 \mathrm{~mm}$ in TL are physiologically mature (Sato et al. 2008).

Market research. We recorded the size and sex of harvested crabs at a local restaurant from early April to mid December 2008. This restaurant is most famous for serving coconut crab dishes to locals and tourists; thus, the number of coconut crabs served here has been outstanding among restaurants in the archipelago (T. Sato pers. comm. with local people). The restaurant receives crabs shipped from several islands within the archipelago, including Hatoma Island, from April to December. Catches during winter months are few. Obtained crabs were sexed according to the presence of pleopods, which are possessed only by females (Fletcher 1993). The TL was measured to the nearest $0.1 \mathrm{~mm}$ using Vernier calipers (Mitutoyo, CD-20PM).

Population structure. We investigated the sex and TL of individuals in the harvested population from early June to late August 2007. Crabs were captured by hand all over the island, and then sex and TL were recorded. We marked the carapace of each captured individual with paint before release to decrease the risk of redundant specimen counts. In this way, we estimated the means and medians of the TL for each sex in the population. The difference between the TL means (male TL - female TL) was also calculated because this difference has been attributed to the harvesting pattern, i.e. a smaller difference indicates higher exploitation pressure (Fletcher et al. 1991). We examined whether the sex ratio of the harvested population skews toward either sex using the $\chi^{2}$-test.

Size of males participating in reproduction. The TL of males participating in reproduction was estimated using the spermatophore volume attached to female abdomens. Mated females retaining spermatophores were captured by hand all over the island from early June to early July in 2007 and 2008. Some spermatophores were collected randomly from several parts of the attached spermatophore mass per female with a pair of tweezers. The spermatophores were brought to the laboratory and 20 sound spermatophores per female were measured. The mean volume was calculated according to Sato et al. (2008). The TL 
of mated males can be estimated from volume based on the linear relationship between male TL and the spermatophore volume (mean volume of spermatophore $\left(\mathrm{mm}^{3}\right)=0.017 \times \mathrm{TL}(\mathrm{mm})-0.031, \mathrm{r}^{2}=0.83$; Sato et al. 2008). Simple linear regression was used to determine the relationship between the TL of mated females and the estimated TL of its mate.

Size differences between males and females in mating pairs and mating success. We investigated the effects of the difference in body size between males and females in mating pairs on mating success by conducting mating trials in the laboratory. Males were captured in late May just before the reproductive season and females were captured during early June to mid July in 2007 and 2008. In the laboratory, the crabs were kept individually in lidded plastic boxes $(60 \times$ $39 \mathrm{~cm}, 27 \mathrm{~cm}$ deep) with flow-through fresh water (3 cm deep). Crabs were fed with an artificial diet (dog food, CB Foods) everyday. In the box, a plastic case $(30.5 \times 30.5 \mathrm{~cm}, 7.0 \mathrm{~cm}$ high $)$ was placed to provide a space where the crab could emerge from fresh water. Additionally, a plastic container $(17 \times 17 \mathrm{~cm}, 6 \mathrm{~cm}$ deep) that was filled with filtered seawater was also provided. The light:dark regime matched the natural local conditions.

Female pleonal expansion has a strong relation to female reproductive activities, and the index of pleonal expansion (PE) can be applied as a morphological criterion for selecting females that are able to mate (Sato \& Yoseda 2009). Coconut crabs have 4 tergites, and the distance between the tergites increases when the pleon becomes enlarged. Thus, the PE is calculated from the distances between the tergites. After measurement of female TL, distances between the 2nd and 3rd tergites $(A)$ and between the 3rd and 4 th tergites $(B)$ were also measured to the nearest $0.1 \mathrm{~mm}$ using Vernier calipers to calculate the $\mathrm{PE}$ using the formula $\mathrm{PE}=(A+B) / \mathrm{TL}$. All females showing a $\mathrm{PE}$ value $>0.35$ can mate, while some females with a PE value of only $\sim 0.30$ also can mate (Sato \& Yoseda 2009).

Mating trials were conducted during early June to mid July in 2007 and 2008, and only individuals with a complete set of limbs were selected. We used 56 males (25.0 to $58.5 \mathrm{~mm} \mathrm{TL}$; mean $\pm \mathrm{SD}, 35.2 \pm 7.6 \mathrm{~mm} \mathrm{TL}$ ) and 56 females $(28.7$ to $37.5 \mathrm{~mm}$ TL; mean $\pm \mathrm{SD}, 33.8 \pm$ $2.1 \mathrm{~mm}$ TL) showing PE values $>0.30$ to form mating pairs at random.

At $\sim 20: 00 \mathrm{~h}$, a single unmated male was placed into a 2001 (85 cm diameter $\times 55.5 \mathrm{~cm}$ height) circular tank a few minutes before the mating trial, in which an artificial turf ( $15 \mathrm{~mm}$ long) was added to the tank bottom for footing. After a male acclimatization period, an unmated female was placed in the tank. The next morning at 08:00 $\mathrm{h}$, we checked whether sper- matophores were attached to the female's abdomen to judge if mating had been successful. If no attached spermatophores were observed, the male and female were returned into each lidded plastic box and the mating trial was again conducted with the same individuals on the next night. If the female did not mate in the second trial, we considered the male to have no ability to mate with the female although it was sexually mature. Each female was used only in a single mating pair, while each male was used until its first successful mating. Using a nonlinear modeling procedure in SPSS 10.0 , the mating success of pairs ( $S$ : success $=1$ or failure $=0$ ) was fitted to the logistic model:

$$
S=1 /[1+\exp (a+b \times \text { Difference })]
$$

where $a$ and $b$ are parameters of the logistic function. The difference in TL between males and females with $50 \%$ mating success $\left(\mathrm{MS}_{50}\right)$ was estimated from the logistic curve.

We also checked whether individuals were injured (e.g. external wounds, lost limbs) or died. The proportion of casualties (injured and/or dead individuals) for every $5 \mathrm{~mm}$ difference in TL between males and females was calculated.

\section{RESULTS}

\section{Market research}

The harvesting pattern was sex- and body sizebiased, in which larger males (>40 mm TL) were almost exclusively taken $(\sim 21 \times$ as many as females) (mean $\mathrm{TL} \pm \mathrm{SE}$, males: $47.8 \pm 0.2 \mathrm{~mm}$, range: 34.0 to $72.3 \mathrm{~mm}, \mathrm{n}=1055$; females: $41.8 \pm 0.6 \mathrm{~mm}$, range: 34.9 $-58.7 \mathrm{~mm}, \mathrm{n}=50$; Fig. 1a).

\section{Population structure}

The mean TL of males was nearly equal to that of females (mean TL $\pm \mathrm{SE}$, male: $32.3 \pm 0.4 \mathrm{~mm}$, range: 11.4 to $61.2 \mathrm{~mm}$, median: $31.7 \mathrm{~mm}, \mathrm{n}=453$; female: $29.6 \pm$ $0.2 \mathrm{~mm}$, range: 14.9 to $44.6 \mathrm{~mm}$, median: $29.7 \mathrm{~mm}, \mathrm{n}=$ 557; Fig. 1b) and the difference between the sexes was $2.7 \mathrm{~mm}$. The observed sex ratio (male:female $=0.81: 1$ ) was significantly skewed toward females $\left(\chi^{2}=10.71\right.$, $\mathrm{df}=1, \mathrm{p}=0.001$ ).

\section{Size of males participating in reproduction}

A total of 33 females carrying spermatophores on their abdomens were captured (mean TL \pm SD: $32.4 \pm$ $3.3 \mathrm{~mm}$; range: 24.9 to $38.7 \mathrm{~mm}$ ). No spermatophores 


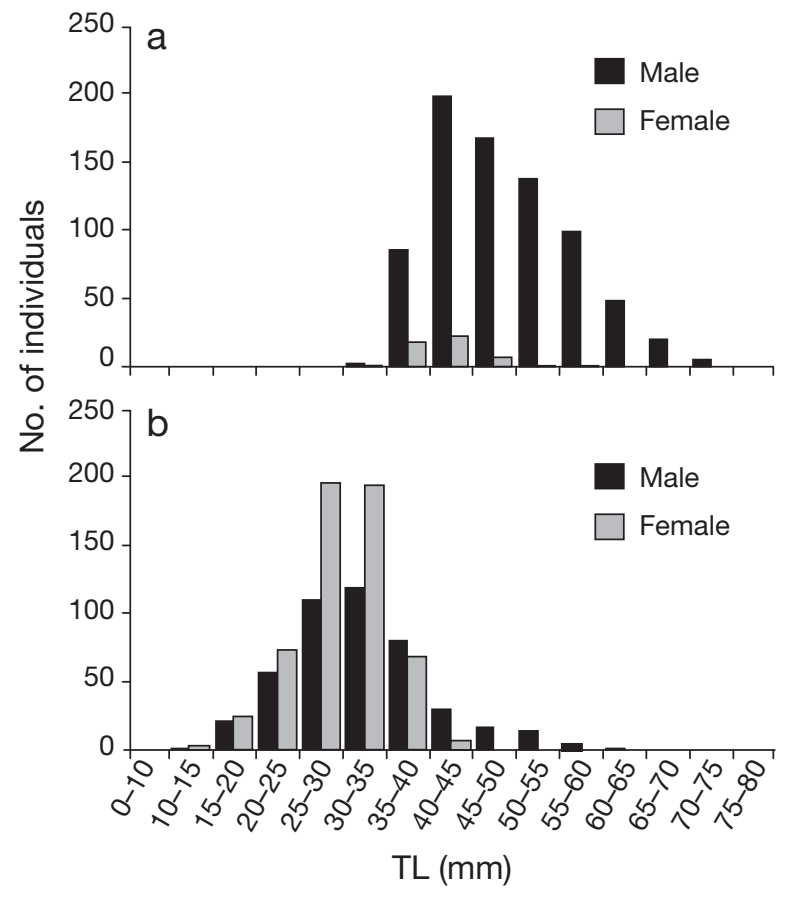

Fig. 1. Birgus latro. (a) Size and sex of individuals marketed for consumption in Ishigaki Island (total male $\mathrm{n}=1055$; total female $\mathrm{n}=50$ ), and (b) size and sex of individuals in the harvested population at Hatoma Island (total male $n=453$; total female $\mathrm{n}=557$ ). TL: thoracic length

that were extremely larger or smaller than others were found among spermatophores collected from a single female, although a wide variation in the volume of spermatophores was observed among females. Therefore, we presumed that all females mated with only 1 male and calculated the TL of the mated male for each female. A simple positive correlation was detected between the TL of the mated female and the estimated TL of its mated male (mean TL \pm SD: $42.1 \pm 9.3 \mathrm{~mm}$; range: 30.9 to $64.9 \mathrm{~mm}$ ), and larger females were found to mate with larger males (estimated TL of mate $=1.15$ $\times$ mated female TL $+4.73 ; \mathrm{r}^{2}=0.16, \mathrm{n}=33, F_{1,31}=6.04$ ， $p=0.02$; Fig. 2), indicating size assortative mating. Of the 33 females captured, 31 were estimated to have mated with a larger male than themselves (Fig. 2). The other 2 females were estimated to have mated with males of approximately equal body size (male - female TL: -0.8 and $-1.8 \mathrm{~mm}$ TL).

\section{Size differences between males and females in mating pairs and mating success}

As result of the mating trials (56 pairs), attachment of spermatophore masses was observed in 33 mating pairs. The spermatophores of these pairs were correctly attached to the female's abdomen. The fitted logistic re-

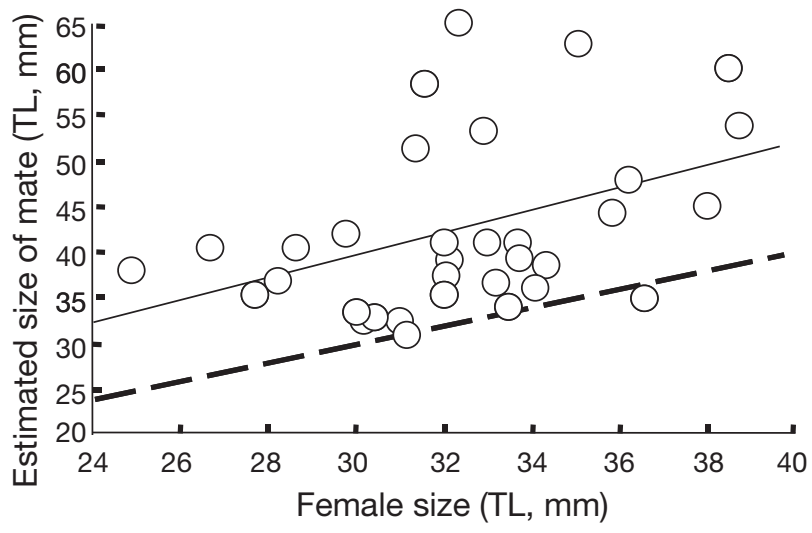

Fig. 2. Birgus latro. Estimated body size of males in each mating pair in the field. Solid line: significant positive relationship between estimated male size and female size (estimated TL of mate $=1.15 \times$ mated female $\mathrm{TL}+4.73 ; \mathrm{r}^{2}=0.16, \mathrm{n}=33, F_{1,31}=$ 6.04, $\mathrm{p}=0.02$ ). Broken line: the same TL for both sexes. TL: thoracic length

gression model was statistically significant (Hosmer and Lemeshow chi-square test: $\chi^{2}=1.199, \mathrm{df}=7, \mathrm{p}=$ 0.991; Cox and Snell's $\mathrm{r}^{2}=0.646 ; a=1.07, \mathrm{SE}=0.785$; $b=-0.97, \mathrm{SE}=0.332 ;$ Wald $\chi^{2}=8.561, \mathrm{df}=1, \mathrm{p}=0.003$ ). By fitting the logistic curve $S=1 /[1+\exp (1.07-0.97 \times$ Difference)], the difference between the TLs of males and females with $50 \%$ mating success was estimated at $1.1 \mathrm{~mm}$ (Fig. 3). When the assigned male was larger than the female in the mating pair $(n=30)$, most females mated except for 1 pair (Fig. 3). When the assigned male was smaller than the female $(\mathrm{n}=26)$, only 4 females mated with the assigned male. In these pairs, females were barely larger than males (male-female TL in 4 mated pairs: $-0.1,-1.6,-1.8$ and $-2.6 \mathrm{~mm}$ ).

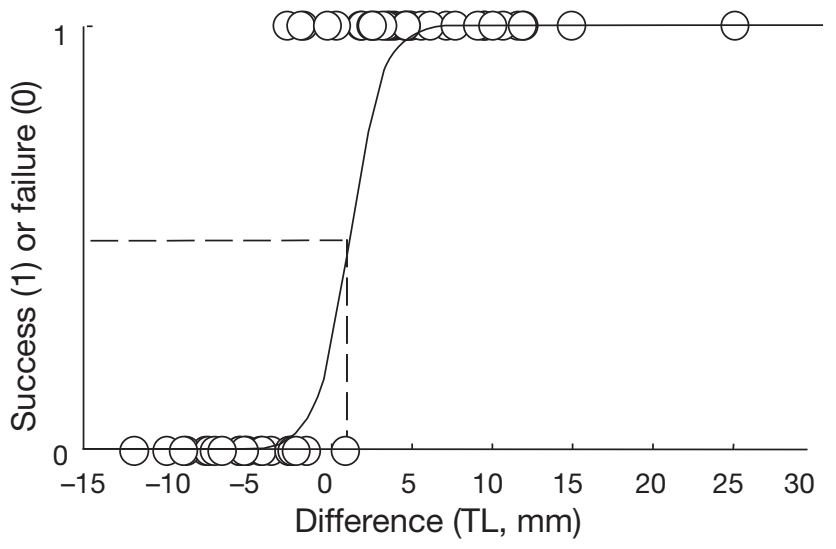

Fig. 3. Birgus latro. Effect of male-female body size difference on mating success. The equation of the logistic curve (solid line) that was fitted to the proportion of mating success is $S=1 /$ [ $1+\exp (1.07-0.97 \times$ Difference)] (Cox and Snell's $\left.\mathrm{r}^{2}=0.646, \mathrm{n}=56\right)$. The residual of $50 \%$ mating success $\left(\mathrm{MS}_{50}\right)$ was estimated as $1.1 \mathrm{~mm}$ TL, indicated by the broken line. TL: thoracic length 
When the male was $\geq 2.5 \mathrm{~mm}$ larger in TL than the female in the mating pair, no casualties occurred (Fig. 4). However, when male TL was approximately equal to that of females or when females were larger than males, casualties were observed. When differences in TL between mates ranged from -2.5 to $2.4 \mathrm{~mm}$ (male - female TL) ( $\mathrm{n}=12$ ), 1 male was found dead, and 2 males were injured. Three females were also injured. When females were larger in TL than males (by $\geq 2.6 \mathrm{~mm}$ ), no female casualties were observed. In contrast, the proportion of male casualties was high especially when females were $>7.6 \mathrm{~mm}$ larger $(\mathrm{n}=5)$.

\section{DISCUSSION}

Larger individuals were harvested selectively more than smaller individuals in the coconut crab, as in many other biological resources (Fenberg \& Roy 2008). Furthermore, the harvesting pattern was extremely biased to male crabs, although there is no regulation against the catching of females. This unique harvesting pattern must have resulted from the prevailing concept among locals that protecting spawning females and smaller males from harvesting will be sufficient to sustain the coconut crab resource even if larger males are excessively removed from the population (T. Sato pers. comm. with local people). Large male-only harvesting, like the harvesting pattern for coconut crabs, is implemented for many commercial crabs (Ennis et al. 1990, Sato et al. 2005b), ungulates

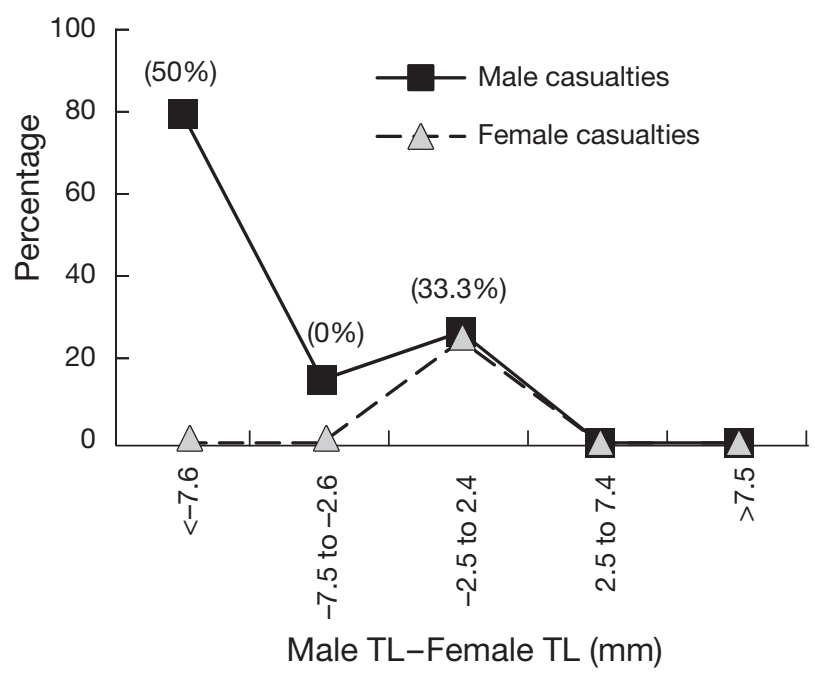

Fig. 4. Birgus latro. Relationship between casualties (\% injured or dead individuals) and body size difference within mating pairs. Numbers in parentheses are percentages of dead crabs among casualties in each size class (male TL - female TL: $<-7.6, \mathrm{n}=5 ;-7.5$ to $-2.6, \mathrm{n}=13 ;-2.5$ to $2.4, \mathrm{n}=12$; 2.5 to $7.4, \mathrm{n}=15 ;>7.5, \mathrm{n}=11)$. TL: thoracic length and carnivores (Ginsberg \& Milner-Gulland 1994, Milner et al. 2007). In this pattern of harvesting, mean male size decreases and the sex ratio skews toward females (Coltman et al. 2003, Sato et al. 2005b, Milner et al. 2007). In the investigated coconut crab population, sex ratio was skewed significantly toward females and the mean male size decreased. The mean and median TL of males was nearly equal to those of females in the investigated population; nevertheless, coconut crabs usually exhibit clear sexual size dimorphism in which the mean body size of females is 20 to $25 \%$ smaller than that of males (Fletcher et al. 1991). The disappearance of sexual size dimorphism, i.e. the decrease in mean male size, might be a result of the present large male-selective harvesting.

In the investigated population, larger females mated with larger males. Such size assortative mating has been reported throughout the animal kingdom, and is generally considered to have evolved through sexual selection (Crespi 1989). In the investigated population in which there must be several processes of inter- and intra-sexual selection, e.g. competition for mates and mate choices, most females were estimated to mate with males that were larger than or approximately equal to them in size, and larger males tended to mate with larger females. Also in the mating trials in which there was inter-sexual selection, females only mated with males that were larger than or approximately as large as them. Although our experiments were not designed to examine female mate choice, these results suggest female preference for larger males and that female choice is one of the main causes of size assortative mating. In coconut crabs, there is a size advantage in struggles with other individuals for physical control, regardless of sex (Helfman 1979). When males were approximately equal to females in TL or especially when females were larger than males in mating pairs, male casualties increased and mating success was low, which might imply that females physically rejected mating attempts by smaller males.

In many anomuran crabs, e.g. Paralithodes brevipes (Sato et al. 2005b, 2006) and Hapalogaster dentata (Sato \& Goshima 2006, 2007a), larger females can mate with males that are much smaller than themselves. However, no coconut crab females mated with males that are much smaller than themselves, suggesting that coconut crab females would gain more benefits by favoring larger males or conversely, reduce benefits by mating with smaller males. In anomuran crabs, the size dependent reproductive potential of males might be one factor that is responsible for female preference for larger males (Sato \& Goshima 2007a). Larger males retain larger sperm reserves (Sato et al. 2005b, Sato \& Goshima 2006) and provide larger ejaculates than smaller males, even after successive matings (Sato et 
al. 2006). Thus, females incur costs from mating with smaller males since it can result in low fertilization rate (Sato et al. 2006, Sato \& Goshima 2007a). Size dependent reproductive potential of males could also be observed in coconut crabs, in which larger males retain larger sperm reserves (Sato et al. 2008). Further studies focusing on female mate preference and the relationship between male body size and the number of ejaculated sperm or fertilization ability should be conducted.

The large male-selective harvesting of coconut crabs could lead to depletion of the resource through a decline in reproductive output as seen in other biological resources. The changes in population structure due to large male-only harvesting can influence the mating system and depress reproductive rate, and may even cause total reproductive collapse in some extreme cases (Milner et al. 2007). Males generally show size dependent reproductive potential; larger males dominate in male-male competition for resources or mates (e.g. Andersson 1994) and are therefore preferred by females (Sato \& Goshima $2007 b)$, resulting in larger males disproportionately contributing to reproduction of populations through sexual selection. Therefore, when the harvesting is biased strongly to large males with a high reproductive value, the reproductive rate of the population can decrease (Fenberg \& Roy 2008), e.g. through sperm limitation (Ginsberg \& Milner-Gulland 1994, Sato \& Goshima 2006, Sato et al. 2007).

Removal of breeding individuals, i.e. larger males in coconut crabs, from the population can also negatively affect female reproductive success by reducing the probability of encountering potential mates (Moller \& Legendre 2001). In fished populations of some large decapod species, a decrease in male density due to large male-only fishing reduces mate availability for females and makes it difficult to find suitable mates (Ennis 1980). Availability or encounter rate between females and suitable mates might have been low in the investigated population especially for larger females despite the larger contribution of larger females to the reproductive rate due to the exponential increase in fecundity with female body size (Sato \& Yoseda 2008). Perhaps, some females might have failed to meet suitable mates within their receptive period of mating, and suffered reduced reproductive success from delayed mating. Some negative effects of delayed mating on spawning, fertilization, and development of eggs have been reported in anomuran crabs (e.g. Sato et al. 2005a, Sato \& Goshima 2006). In the investigated population, some females actually had clearly small or nonfertilized clutches (T. Sato unpubl. data), implying that the females might have failed to mate within the optimal timing in the field.
To avoid such expected negative impacts of large male-selective harvesting on the reproduction of coconut crabs, we must establish management strategies that take into consideration that large male body size in coconut crabs is a sexually selected character that contributes positively to the reproduction of the resources. Generally, protection of spawning females from harvesting is effective to sustain the reproductive rate of resources and recover from resource depletion. Although selective harvesting of males leads to female-biased sex ratios, it does not necessarily lead to a reduction in reproductive rate because most harvested species show polygynous mating systems (Mysterud et al. 2002). In many cases, reproductive rates are therefore resilient to a skewed sex ratio (Milner et al. 2007) and might even increase (Solberg et al. 2000). However, we must pay attention to excessive decreases not only in the availability of suitable mates for females, i.e. the abundance of larger males in coconut crabs, but also in the probability of encountering potential mates among sexes due to excessive harvesting.

Thus, we recommend male-only harvesting with slot size limits as an effective management measure for coconut crabs. Under this management measure, intermediate size males are harvested selectively, and all females, juvenile males, smaller adult males just after maturation, and large males with a high reproductive value are protected from harvesting. Protection of large males with a high reproductive value by a maximum legal size limit will sustain the reproductive rate of populations. Additionally, a minimum legal size limit should be determined by the functional maturity size to allow all individuals to mate at least once before being harvested (Myers \& Mertz 1998), which might prevent serious depression in male reproductive potential and genetic diversity of the resource. The narrow window of vulnerability for harvesting will mitigate the decrease in population density due to harvesting. However, caution should be exercised as excessive large male-only harvesting can decrease the sex ratio below the threshold to sustain the reproductive rate of populations (Sato \& Goshima 2006). Thus, the details of the mating system and size dependent reproductive potential of male coconut crabs must be investigated to understand the optimal sex ratio that will ensure sufficient availability of males for all females to mate, which will contribute to the determination of an optimal maximum legal size for coconut crabs. Of course, regulating the total number of harvested males from the narrow window is also essential to allow intermediate size males to survive and become large proficient males.

The male-only harvesting with slot size limits for coconut crabs would not only reduce the risk of failure 
in female mating but might also be able to mitigate negative evolutionary responses to size selective harvesting by protecting larger males. Harvesting has been implicated in evolutionary changes of heritable traits. For example, size selective harvestings have caused a significant reduction in age and length at maturity through the removal of larger individuals (Conover \& Munch 2002, Hutchings 2005). These fishing-induced evolutionary changes can reduce yields from harvested resources (Conover \& Munch 2002) and might even affect population viability (Walsh et al. 2006) and eventually, recovery from collapse (Hutchings 2005). Establishing an optimal maximum size limit could be a useful tool in reducing such anthropogenic selection and in protecting long-term biomass yield (Conover \& Munch 2002, Baskett et al. 2005). Optimal management regimes that take into consideration the ecological and evolutionary consequences of large male-only fishing must be established for coconut crab resources in order to develop truly sustainable coconut crab harvesting.

Acknowledgements. We thank the residents of Hatoma Island for their generous hospitality and cooperation, and E. Kinjyo, the master storekeeper of Kin-Pachi. We also thank 3 anonymous reviewers, K. Okuzawa, C. L. Roberto, and the staff members of the Ishigaki Tropical Station, Seikai National Fisheries Research Institute, for helpful comments and discussions. This study was supported by a Grant-in-aid for Science Research (No. 20710184, to T.S.) from the Ministry of Education, Culture, Sports, Science and Technology of Japan.

\section{LITERATURE CITED}

Andersson M (1994) Sexual selection. Princeton University Press, Princeton, NJ

Aquiloni L, Gherardi F (2008) Mutual mate choice in crayfish: large body size is selected by both sexes, virginity by males only. J Zool (Lond) 274:171-179

Baskett ML, Levin SA, Gaines SD, Dushoff J (2005) Marine reserve design and the evolution of size at maturation in harvested fish. Ecol Appl 15:882-901

Berkeley SA, Chapman C, Sogard SM (2004) Maternal age as a determinant of larval growth and survival in a marine fish, Sebastes melanops. Ecology 85:1258-1264

Brown IW, Fielder DR (1991) Project overview and literature survey. In: Brown IW, Fielder DR (eds) The coconut crab: aspects of Birgus latro biology and ecology in Vanuatu. ACIAR Monograph 8:1-11

Coltman DW, O'Donoghue P, Jorgenson JT, Hogg JT, Strobeck C, Festa-Bianchet M (2003) Undesirable evolutionary consequences of trophy hunting. Nature 426: $655-658$

> Conover DO, Munch SB (2002) Sustaining fisheries yields over evolutionary time scales. Science 297:94-96

Crespi BJ (1989) Causes of assortative mating in arthropods. Anim Behav 38:980-1000

Einum S, Fleming IA (1999) Maternal effects of egg size in brown trout (Salmo trutta): norms of reaction to environmental quality. Proc R Soc Lond B Biol Sci 266:2095-2100
Ennis GP (1980) Size-maturity relationships and related observations in Newfoundland populations of the lobster (Homarus americanus). Can J Fish Aquat Sci 37:945-956

Ennis GP, Hooper RG, Taylor DM (1990) Changes in the composition of snow crab (Chionoecetes opilio) participating in the annual breeding migration in Bonne Bay, Newfoundland. Can J Fish Aquat Sci 47:2242-2249

Fenberg PB, Roy K (2008) Ecological and evolutionary consequences of size-selective harvestings: How much do we know? Mol Ecol 17:209-220

Fletcher WJ (1993) Coconut crabs. In: Wright A, Hill L (eds) Nearshore marine resources of the South Pacific. University of the South Pacific, FFA, and ICOD, Suva, p 643-681

Fletcher WJ, Brown IW, Fielder DR (1991) Structure and dynamics of populations of coconut crab in Vanuatu. In: Brown IW, Fielder DR (eds) The coconut crab: aspects of Birgus latro biology and ecology in Vanuatu. ACIAR Monograph 8:61-85

Ginsberg JR, Milner-Gulland EJ (1994) Sex-biased harvesting and population dynamics in ungulates: implications for conservation and sustainable use. Conserv Biol 8: $157-166$

Helfman GS (1979) Coconut crabs and cannibalism. Nat Hist 88:77-83

> Hoefler CD (2007) Male mate choice and size-assortative pairing in a jumping spider, Phidippus clarus. Anim Behav 73:943-954

Hutchings JA (2005) Life history consequences of overexploitation to population recovery in Northwest Atlantic cod (Gadus morhua). Can J Fish Aquat Sci 62:824-832

IUCN (2009) Red list of threatened species. International Union for Conservation of Nature and Natural Resources. www.redlist.org, accessed 9 June

- Kolm N (2002) Male size determines reproductive output in a paternal mouthbrooding fish. Anim Behav 63:727-733

> Milner JM, Nilsen EB, Andreassen HP (2007) Demographic side effects of selective hunting in ungulates and carnivores. Conserv Biol 21:36-47

> Moller AP, Legendre S (2001) Allee effect, sexual selection and demographic stochasticity. Oikos 92:27-34

Myers RA, Mertz G (1998) The limits of exploitation: a precautionary approach. Ecol Appl 8 (Suppl 1):S165-S169

> Mysterud A, Coulson T, Stenseth NC (2002) The role of males in the dynamics of ungulate populations. J Anim Ecol 71:907-915

Real L (1990) Search theory and mate choice. 1. Models of single-sex discrimination. Am Nat 136:376-405

> Sato T, Goshima S (2006) Impacts of male-only fishing and sperm limitation in manipulated populations of an unfished crab, Hapalogaster dentata. Mar Ecol Prog Ser 313:193-204

> Sato T, Goshima S (2007a) Effects of risk of sperm competition, female size, and male size on number of ejaculated sperm in the stone crab Hapalogaster dentata. J Crustac Biol 27:570-575

> Sato T, Goshima S (2007b) Female choice in response to risk of sperm limitation by the stone crab Hapalogaster dentata. Anim Behav 73:331-338

Sato T, Yoseda K (2008) Reproductive season and female maturity size of coconut crab Birgus latro on Hatoma Island, southern Japan. Fish Sci 74:1277-1282

Sato T, Yoseda K (2009) Prediction of timing of mating and egg extrusion in the coconut crab Birgus latro judged from female pleonal expansion. Fish Sci 75:641-648

Sato T, Ashidate M, Goshima S (2005a) Negative effects of delayed mating on the reproductive success of female spiny king crab, Paralithodes brevipes. J Crustac Biol 25:105-109 
Sato T, Ashidate M, Wada S, Goshima S (2005b) Effects of male mating frequency and male size on ejaculate size and reproductive success of female spiny king crab, Paralithodes brevipes. Mar Ecol Prog Ser 296:251-262

Sato T, Ashidate M, Jinbo T, Goshima S (2006) Variation of sperm allocation with male size and recovery rate of sperm numbers in spiny king crab Paralithodes brevipes. Mar Ecol Prog Ser 312:189-199

Sato T, Ashidate M, Jinbo T, Goshima S (2007) Does maleonly fishing influence reproductive success of female spiny king crab, Paralithodes brevipes? Can J Fish Aquat Sci 64:735-742

Sato T, Yoseda K, Abe O, Shibuno T (2008) Male maturity,

Editorial responsibility: Hans Heinrich Janssen, Oldendorf/Luhe, Germany number of sperm and spermatophore size relationships with male size in coconut crab Birgus latro in Hatoma Island, southern Japan. J Crustac Biol 28:663-668

Shokita S (2006) Coconut crab. In: Nature Conservation Bureau, Japan Ministry of the Environment (ed) Red data book on crustaceans. Japan Wildlife Research Center, p 54 (in Japanese)

Solberg EJ, Loison A, Saether BE, Strand O (2000) Age-specific harvest mortality in a Norwegian moose Alces alces population. Wildl Biol 6:41-52

Walsh MR, Munch SB, Chiba S, Conover DO (2006) Maladaptive changes in multiple traits caused by fishing: impediments to population recovery. Ecol Lett 9:142-148

Submitted: July 13, 2009; Accepted: October 12, 2009 Proofs received from author(s): January 29, 2010 